the therapy of shock and of anaphylactic œdema one important fact emerges-adrenalin in large doses has no beneficial effect in shock and often grave potentialities if given in excess and an immediate beneficial effect in the anaphylactic state.

The book is well and clearly written, the literature well reviewed and the pros and cons of each fact fairly put and argued. It should be read by all who may have to deal with shock cases in the near future.

\section{A TREATISE ON THE SURGICAL TECHNIQUE OF OTORHINOLARYNGOLOGY.}

By Professor Georges Portmann. Baillière, Tindall \& Cox. 1939. Price 57s. Od.

Operative surgery is one of the branches of medicine where individual and modern methods in technique, so aptly carried out by the operator, may lack that clarity of description necessary in any essentially practical treatise. But here the author has succeeded, for he has cleverly eliminated much of the superfluous phrasing so often found in works of this kind, and has confined himself to language which essentially deals with, and is entirely relevant to, the stages of the various procedures. The result is a clear concise work which should prove an immense help to the student and a splendid work of reference to the consultant.

An outstanding merit of this work is the profound illustrations and diagrams. These are indeed very instructive, for with them the successive stages of even the most complicated operation are followed with ease; these diagrams save a large amount of written material which, however concisely put, may still not succeed in conveying to the reader's mind a picture of what is intended.

It is pleasing to note that so much importance is attached to pre- and post-operative treatment; it matters not whether a minor or major operation is involved, the care and trouble taken in these respects have a direct bearing on a successful issue-pleasing both to patient and surgeon.

The author is perhaps unique in insisting upon an assistant's table for instruments, as well as his own; one would imagine this would be a hindrance rather than a help.

Especially valuable are the accounts of antrotomy in the infant, trephination of the sphenoidal sinus by the septal or turbinate ties, removai of tumours of the nasal fossæ and accessory cavities, with illustrations of exenteration of the orbit.

The author devotes a section to his method of performing a tonsillectomy. He prefers to have the patient seated, the head held by an assistant, and a local anæsthetic. This would indeed appear a rather crude procedure, at all events in this country; bleeding is very often troublesome and, under these circumstances, one would imagine a most uncomfortable situation for both surgeon and conscious patient with his mouth gagged widely open. It is essentially a method only to be used by one skilled in the technique, and so rather difficult of attainment.

The man in general practice in the country, called upon to perform any of the emergency operations portrayed in this book can, with greatly enhanced confidence, undertake such if he possesses a copy of this treatise.

\title{
Miscellaneous.
}

This Section deals with New Drugs, Preparations, Surgical Instruments, etc. The description of each article is supplied by the Producer. Particulars regarding insertions, which are free of cost, may be obtained from the Business Manager, Fellowship of Medicine and Post-Graduate Journal, 404, Grand Buildings, W.C.2.

Roche Products Ltd. have issued a booklet concerning their product EPHYNAL, which is described as "the Roche fertility vitamin." This literaProducts ture deals with the properties, Ltd. functions and uses of Vitamin $\mathrm{E}$ which is, of course, commonly known as the fertility vitamin.

The subject is naturally concerned with fertility and it is stated-as is known-that wheat germ oil has been used for such conditions as habitual and threatened abortion for several years. It is only, however, as the leaflet points out, quite recently that the active principle of this oil, namely $a$-tocopherol, has been synthesised so that its manufacture is possible on a technical scale.

This old-established firm is now producing vitamin $E$ under the trade name of EPHYNAL.

Any further information regarding this particular product will be willingly supplied by Roche Products Ltd., Broadwater Road, Welwyn Garden City, Herts. 